\title{
Endangered species augmentation: a case study of alternative rearing methods
}

\author{
Josh E. Rasmussen*, Mark C. Belk, Steven L. Peck \\ Department of Biology, Brigham Young University, Provo, Utah 84602, USA
}

\begin{abstract}
Stocking of artificially propagated fish has been adopted by many endangered fish recovery programs as a key component of their recovery plans. However, quantifying successful recruitment of individuals to the adult population is difficult, especially in long-lived species. To evaluate the effect of the rearing environment on recruitment in the native environment, we compared post-stocking survival of the endangered June sucker Chasmistes liorus reared under conventional hatchery practices to those reared in 2 reservoirs. We used logistic regression analysis to compare patterns of survival among populations including total length and condition at the time of stocking as continuous covariates. The estimated probability of survival for reservoir-reared fish from Red Butte and Camp Creek Reservoirs was 0.19 and 0.05 , respectively, compared to 0.05 for hatchery-reared fish. Length and condition were positively related to post-stocking survival. On average, reservoirreared fish performed better than hatchery-reared fish. It is not clear what mechanism led to increased survival for the Red Butte source, but several studies have demonstrated the importance of acclimation to the physical environment and the threat of predation. We suggest that augmentation procedures would produce more recruits to the adult population if they incorporate grow-out or at least acclimation in more natural environments than that provided by hatcheries prior to release in Utah Lake.
\end{abstract}

KEY WORDS: Post-stocking survival $\cdot$ Semi-natural rearing $\cdot$ Chasmistes liorus

\section{INTRODUCTION}

Many species of fish have exhibited dramatic population declines over the last 2 centuries (Moyle \& Leidy 1992, Bruton 1995, Leidy \& Moyle 1997, Ricciardi \& Rasmussen 1999). In general, population decline can be attributed to overexploitation, habitat degradation and loss, and introduction of non-native species. In response, conservation actions have included restriction of harvest, habitat restoration, non-native species control, and artificial propagation and repatriation programs. However, in many instances adequate monitoring programs are not in place, and the effectiveness of a given management activity often is not clearly understood (Anders 1998, Palmer et al. 2005).

Many recovery programs for threatened or endangered fishes include artificial propagation and repat- riation of large numbers of fish to rapidly bolster depleted populations (Hard et al. 1992, Kohler 1995, Ireland et al. 2002a). Artificial propagation can be intense, as exemplified by typical raceway fish hatchery methods used in more common sport fishery programs; an alternative is the use of natural or seminatural ponds or reservoirs that more closely resemble the species' natural environment.

However, recovery programs not only differ in purpose from more traditional fish culture programs, but often the life histories of many imperiled species differ greatly from species typically reared with artificial propagation. For example, traditional hatchery programs are typically targeted for short-term results, i.e. put-and-take programs with turnover rates of less than 1 yr. In contrast, many imperiled fishes, e.g. sturgeon (Ireland et al. 2002b), can live for decades and require 
much more time to accurately assess the effectiveness of repatriation efforts. These and other differences may require that rearing strategies for long-lived fish be distinct from more traditional methods.

The use of hatchery facilities gives the manager a greater degree of control over the population, but there are also drawbacks to such an approach, which can include unintended genetic, behavioral, physiological, and morphological effects that may reduce the viability of individuals once released into the wild (Meffe 1986, Ryman \& Laikre 1991, Le Vay et al. 2007). Reduced fitness and performance among hatcheryreared individuals has been observed in several species (Unwin 1997, Berejikian et al. 2001, Davis et al. 2004). As individuals become acclimated to an artificial environment they may exhibit divergent traits from those exhibited in a natural environment (Belk et al. 2008). In comparison, natural environments may provide relatively better acclimated individuals, but managers have less control over conditions in these systems, and such systems may require more effort and resources to retrieve the fish for repatriation.

For repatriation efforts, the most important metric of success is the number of individuals that recruit into the adult (i.e. reproducing) population (Le Vay et al. 2007). Other metrics, such as total number of fish stocked, are useful in assessing the effectiveness of rearing methods, but consistent recruitment is the key indicator of a successful augmentation and recovery program (Gerber \& Hatch 2002). How well individuals from different rearing environments survive once stocked into a natural system in comparison to each other is unknown in many cases, but it is essential when evaluating recovery efforts to understand the relative efficiency of various methods (Stoskopf 1995).

Population augmentation from hatchery-raised individuals is an important component of the recovery plan for the endangered June sucker Chasmistes liorus (Catostomidae). The species was listed in the USA as federally endangered in 1986 due to low population numbers (estimated to be less than 400 spawning individuals) and a severely restricted range with numerous threats (USFWS 1999, Cooke et al. 2005). Main components of the recovery plan include habitat enhancement, augmentation of the wild population with a large number of hatchery-raised individuals, and establishment of at least 2 refuge populations (USFWS 1999).

June sucker are endemic to Utah Lake, UT, USA, a shallow, freshwater remnant of the ancient Lake Bonneville. They are long-lived (maximum age: $>40 \mathrm{yr}$ ), and sexual maturity occurs at approximately 6 to $10 \mathrm{yr}$ of age, after which growth of individuals continues albeit at a lower rate (Scoppetone \& Vinyard 1991, Belk 1998). Adults attain lengths up to $600 \mathrm{~mm}$ (Whitney \& Belk 2000). The common name is derived from the fact that the annual spawning run occurred historically during June (Jordan 1891). Historic spawning locations may have included many of the major tributaries to the lake, but current spawning is restricted to the lower portion of the Provo River.

Stocking to augment the wild population in Utah Lake has been ongoing since 1994 from a variety of sources; however, the success of these efforts has not been evaluated. Given the extended time to maturity in June sucker, data on successful recruitment to the adult population has only recently become available. We used return data to the spawning run in the Provo River over a 12 yr period to determine the effect of rearing environment (hatchery versus reservoir), body size, and condition on comparative survival and recruitment to the adult population in Utah Lake.

\section{MATERIALS AND METHODS}

Study sites. Utah Lake is at an elevation of $1368 \mathrm{~m}$ with a total surface area of 39214 ha and an average depth of $2.8 \mathrm{~m}$ (Fuhriman et al. 1981). The lake is a shallow basin-bottom lake, and as such tends to be turbid with no stratification. All major tributaries have been dammed or are significantly diverted during the summer months, but the lake also receives some input from springs. Currently the fish fauna of Utah Lake is dominated by introduced carp Cyprinus carpio, white bass Morone chrysops, and black bullhead Ictalurus melas (Heckmann et al. 1981). June sucker are 1 of 2 native species (of 13 native species historically) remaining in the lake, the other being Utah sucker Catostomus ardens (Andersen et al. 2007).

The Fisheries Experiment Station (FES), located in Logan, UT, is operated by the Utah Division of Wildlife Resources (UDWR) and has been used for the recovery of June sucker since 1991. Individuals to be kept and used for brood stock were collected by UDWR through streamside spawns beginning in the late 1980s (Andersen et al. 2007). Fish maintained at the FES were segregated based on family lots, and so densities varied across tanks. Fish in this study reared at this facility were kept in 500 gallon (ca. 1875 l) circular tanks or rectangular troughs with a flow-through system on artesian well water at $15.6^{\circ} \mathrm{C}$ (Andersen et al. 2007). A variety of feeds was used; the most common were pellets such as Nelson's Silver Cup Fish Feed (Nelson \& Sons). Informal assessments of stocking success has prompted several improvements in techniques and facilities at FES for June sucker propagation, including an expanded coldwater facility in 2001, development of a June sucker-specific feed, and especially a warmwater facility in 2006. However, no data for fish reared under these improved conditions are available for this 
analysis given that the first stocking of fish from the new warmwater facility occurred in 2007.

Several locations have been used to establish June sucker refuge populations (Andersen et al. 2007). However, repatriation into Utah Lake has only occurred in significant numbers from 2 of these, Camp Creek and Red Butte Reservoirs. Camp Creek Reservoir is a privately owned reservoir located approximately $358 \mathrm{~km}$ northwest of Salt Lake City (Box Elder County, UT). The reservoir has a maximum depth of $5 \mathrm{~m}$ and approximately 2 ha of surface area (Thompson 2001). June sucker were introduced into the reservoir beginning in 1987 and have established a self-sustaining population (Andersen et al. 2007). Introductions into the reservoir consisted of juveniles that were progeny of individuals collected from streamside spawns and reared at the UDWR hatchery in Springville, UT (USFWS 1999).

Red Butte Reservoir is located at an elevation of 1639 $\mathrm{m}$ in Red Butte Canyon, approximately $2.5 \mathrm{~km}$ northeast of Salt Lake City, UT. The reservoir has an average depth of $5.4 \mathrm{~m}$ (maximum depth $7.5 \mathrm{~m}$ ) with a total surface area of 3.0 ha (Billman 2005). Water temperatures within the reservoir range from $9^{\circ}$ to $20^{\circ} \mathrm{C}$ during the summer (Billman \& Crowl 2007). Aquatic vegetation along the shores was relatively common when the fish were introduced in the early 1990s, but had largely disappeared by 2000. Likewise, a population of large cutthroat trout Oncorhynchus clarki was present when the June sucker were introduced, but had dwindled to a few remaining, but still relatively large, individuals by 2000. A population of June sucker was established in Red Butte Reservoir with progeny taken from streamside spawns as well as surplus brood stock from

Table 1. Chasmistes liorus. Summary statistics for major stocking events of June sucker from 3 locations into Utah Lake since 1994. Events selected for analysis occurred in 1995 and 2001. TL: total length

\begin{tabular}{|lcccc|}
\hline Source & Year & $\begin{array}{c}\text { No. } \\
\text { stocked }\end{array}$ & $\begin{array}{c}\text { No. } \\
\text { recaptures }\end{array}$ & $\begin{array}{c}\text { TL mean } \pm \text { SD } \\
(\mathrm{mm})\end{array}$ \\
\hline Camp Creek & $2001^{\mathrm{a}}$ & 904 & 43 & $266.7 \pm 62.1$ \\
Reservoir & 2004 & 1060 & 2 & $168.0 \pm 53.6$ \\
& 2005 & 862 & 2 & $223.4 \pm 45.5$ \\
Fisheries & 1994 & 1527 & 7 & $202.8 \pm 39.3$ \\
Experiment Station & $1995^{\mathrm{a}}$ & 2873 & 67 & $212.8 \pm 51.0$ \\
& 1996 & 295 & 0 & $261.3 \pm 42.0$ \\
& 1999 & 692 & 3 & $268.4 \pm 36.9$ \\
& 2004 & 3606 & 0 & $162.4 \pm 42.0$ \\
& 2005 & 1029 & 2 & $225.7 \pm 70.3$ \\
Red Butte & & & & \\
Reservoir & $2001^{\text {a }}$ & 700 & 250 & $357.5 \pm 40.1$ \\
a Stocking event included in statistical analysis & & \\
\hline
\end{tabular}

FES in the early 1990 's. This population began to produce sufficient numbers through natural spawning such that transplanting of individuals from the reservoir into Utah Lake became feasible within a decade of its establishment (Andersen et al. 2007).

Field methods. Multiple stocking events from 3 different sources have occurred in Utah Lake beginning in 1994. However, recapture of stocked individuals varies greatly among the events (Table 1). We restricted statistical analysis to stocking events that had sufficient recaptures to permit accurate modeling (i.e. 3 stocking events, 1 each from FES, Camp Creek Reservoir, and Red Butte Reservoir). Research and field techniques were conducted according to handling guidelines and procedures as established by the applicable authorities and subjected to review by the scientists comprising the June Sucker Recovery Implementation Program (JSRIP) Technical Committee prior to being implemented.

In 1995, 2873 June sucker, ranging from 54 to $388 \mathrm{~mm}$ in total length (TL) except 1 individual which measured $466 \mathrm{~mm}$ TL, were stocked into Utah Lake from FES. In 2001, June sucker from Camp Creek Reservoir ( $\mathrm{n}=904 ; 160-446 \mathrm{~mm}$ TL) and Red Butte Reservoir ( $\mathrm{n}=700 ; 200-492 \mathrm{~mm}$ TL) were also stocked into Utah Lake. Information on the age structure for the 2 reservoirs is unavailable for these stocking events. Fish from the hatchery ranged in age from 4 to $6 \mathrm{yr}$, with the majority being $4 \mathrm{yr}$. All individuals ( $\mathrm{n}=$ 4477) were measured (TL), weighed (g), and given a Passive Integrated Transponder (PIT) tag prior to stocking. Stocking locations varied within and among stocking events and included Provo River approximately $2 \mathrm{~km}$ from the lake, and open water and near shore habitats within Utah Lake. Fish from Red Butte were stocked in Provo River in May (68\%) and near-shore habitat in October, whereas those from FES were relatively evenly divided into the river and open water habitats, and those from Camp Creek went into Provo River. Stocking events for Camp Creek and FES occurred in August (99\% and 32\%, respectively) and October in their respective years.

Provo River was monitored annually by the UDWR during the spawning run of the June sucker (approximately April through June). Prior to 2000 and in 2006, individuals were captured using a weir and/or fyke nets situated to capture fish moving up- or downstream. Sampling during 1998 and 1999 was restricted due to high flows in the river, which drastically reduced 
accessibility to the river. Beginning in 2000, the UDWR surveyed the river nightly during the spawning season using powerful handheld spotlights. Once a sucker was detected, a crew of 3 to 4 people would surround the fish and gently direct it into a handheld dip net. Up to 30 individuals a night could be captured with this method, but nightly averages were typically much lower (approximately 5 June suckers). Captured suckers were identified using the PIT tags, and pertinent information was recorded, including size and sex, prior to re-release. Data used in our analyses are based on monitoring efforts during 1995 to 2007 of the spawning run in the Provo River.

In total, 358 individuals (67 from FES, 250 from Red Butte, and 41 from Camp Creek) were recaptured. Lengths at stocking for recaptured individuals ranged from $125 \mathrm{~mm}$ to $486 \mathrm{~mm}$. The average number of years until first recapture varied among the sources. Individuals from Red Butte averaged 2.2 yr until first recapture; Camp Creek averaged 3.3 yr and FES 6.1 yr.

Outliers from the entire dataset, based on length at the time of stocking, were identified using standard techniques (Zar 1999) and excluded, bringing the total number of individuals included in the analysis to 4388 . Sixty outliers from FES, 7 from Camp Creek, and 22 from Red Butte were excluded. The majority of outliers from FES appeared to be due to transcription errors of the length values, e.g. misplacement of the decimal point; however, since we do not have specimens to verify data, we opted to exclude these individuals. Total recaptures included in the final dataset, after outliers were removed, included 66 from FES, 248 from Red Butte, and 41 from Camp Creek.

Statistical methods. Parametric logistic regression modeling, using the R package Design (Harrell 2007, R Development Core Team 2008), was used to explore the effect of source population, TL, and condition (as represented by relative weight; $W_{\mathrm{r}}$ ), on probability of post-stocking survival (Hosmer \& Lemeshow 2000, Harrell 2001). Survival was the variable of interest in this analysis, and no distinction was made on the time until recapture or total number of recaptures for individual fish. For example, individuals recaptured for the first time $10 \mathrm{yr}$ after stocking received the same score as individuals recaptured the first year after stocking; each was scored as a '1.' Individuals never recaptured were scored as a '0.' Sex was not included as a factor in the model, because sexes are indistinguishable in juvenile June suckers; therefore, the sex of individuals that were stocked but never recaptured is unknown.

To determine if body condition differences significantly affected survival after stocking, a body condition factor, relative weight $\left(W_{\mathrm{r}}\right)$, was calculated for inclusion in the model as a covariate instead of simply untransformed weight. The condition factor was derived by comparing an individual's observed weight to its length-specific expected weight $\left(W_{\mathrm{s}}\right)$, as predicted from a linear regression $\left(\mathrm{df}=4388, \mathrm{r}^{2}=0.982\right.$, $\mathrm{p}<0.0001)$ on all individuals used in this analysis (Wege \& Anderson 1978, Pope \& Kruse 2007). Expected weights of each individual were calculated from the equation $\log _{10}\left(W_{\mathrm{s}}\right)=-4.82+2.92 \times \log _{10}(\mathrm{TL})$, back-transformed, divided into the observed weight of each individual, and multiplied by 100 to obtain $W_{\mathrm{r}}$.

Spearman's $\rho$ rank correlation was used as a general-purpose measure of association of the factors (i.e. $\mathrm{TL}$ and $W_{\mathrm{r}}$ at the time of stocking) with the response variable (survival) to allow for pre-specification of predictor complexity (Harrell 2001). We then transformed continuous variables using a restricted cubic spline to account for potential non-linearity in the relationship between variables and the survival response (Stone \& Koo 1985). The number of knots used for each variable depended on the available degrees of freedom and the variable's relative importance given Spearman's $\rho$ test (Harrell 2001).

Based on this analysis, a stronger association existed between survival and TL than with $W_{\mathrm{r}}$ (adjusted $\rho^{2}=$ 0.11 and 0.02 , respectively); therefore, to capture this possible ordering, we allowed the restricted cubic spline of TL to be more complex (knots $=7$ ). Relative weight was assigned 5 knots. Both variables, as well as nonlinear transformations (i.e. restricted cubic spline), were retained in our final model (Table 2), which significantly described variation in survival based on a drop-in-deviance test $\left(\chi^{2}=515.2, \mathrm{df}=12, \mathrm{p}<0.0001\right)$.

Model performance was evaluated using area under the Receiver Operator Curve (ROC), Somers' rank correlation index $\left(D_{\mathrm{xy}}\right)$, and an enhanced bootstrap method that estimates bias in the model due to overfitting or 'optimism' (Enfron \& Tibshirani 1993, Hosmer \& Lemeshow 2000, Harrell 2001). Predictive accuracy of the model is determined by comparing observed parameter values to bootstrap estimates (i.e. index of accu-

Table 2. Chasmistes liorus. Results of a drop-in-deviance test of logistic regression model of survival of individuals stocked into Utah Lake from 3 sources (Camp Creek Reservoir,

Fisheries Experiment Station, and Red Butte Reservoir)

\begin{tabular}{|lccr|}
\hline Factor & $\chi^{2}$ & df & \multicolumn{1}{c|}{$p$} \\
\hline Source & 72.13 & 2 & $<0.001$ \\
Total length & 73.06 & 6 & $<0.001$ \\
Nonlinear & 14.88 & 5 & 0.011 \\
Relative weight & 9.33 & 4 & 0.053 \\
Nonlinear & 9.28 & 3 & 0.026 \\
Total nonlinear & 26.67 & 8 & 0.001 \\
Total & 515.24 & 12 & $<0.001$ \\
\hline
\end{tabular}


racy), which thereby provides an estimate of bias in the model parameters (Harrell 2001).

\section{RESULTS}

Of the 11 stockings of June sucker that have occurred into Utah Lake from all sources, only 4 have yielded more than 10 total recaptured individuals (Table 1). The remaining 7 have an average recapture rate of $0.2 \%$. In all likelihood, the majority of individuals from the later stockings (after 2003) have not had sufficient time to mature and recruit into the spawning population. Nevertheless, only 1 of these stocking events appears promising (Red Butte Reservoir 2005), from which 294 individuals $(3.5 \%)$ were captured within 2 yr after stocking.

Logistic regression modeling revealed significant differences of survival among individuals from Red Butte Reservoir compared to those from Camp Creek Reservoir and FES (Fig. 1). The probability of survival of individuals from Camp Creek Reservoir and FES are identical, odds ratio $(\mathrm{OR})=1.01$ (95\% confidence interval [CI]: 0.63-1.62). The odds of surviving for an individual from Red Butte Reservoir are 5.07 (95\% CI: 3.21-8.03) times greater than individuals from either of the other sources.

Total length at the time of stocking was also an important predictor of survival probability (Fig. 2). Overall, TL was positively related to survival probability. The OR comparing an individual measuring $302 \mathrm{~mm}$ $\mathrm{TL}$, the 75th percentile of lengths of the dataset, to an individual $190 \mathrm{~mm} \mathrm{TL}$, the 25th percentile, is 4.77 (95\% CI: 2.12-10.76). Although $W_{\mathrm{r}}$ was kept in the model based on a drop-in-deviance chi-squared test, the OR comparing the quartiles (92 to 107, respectively) revealed no apparent difference in the odds of survival (1.15, $95 \%$ CI: 0.78-1.69). This apparent dis-

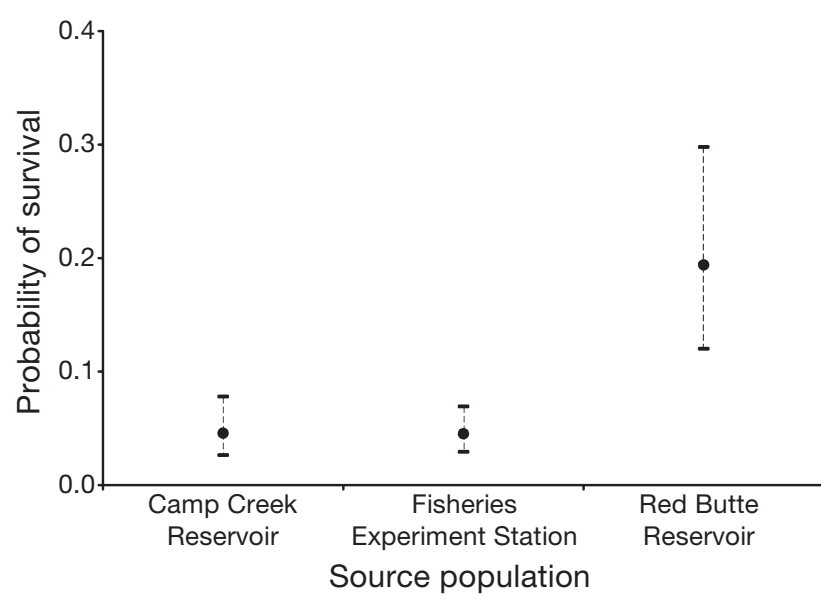

Fig. 1. Chasmistes liorus. Probability of survival of individuals from 3 source populations based on a logistic regression model. Error bars represent $95 \%$ confidence intervals crepancy of retaining $W_{\mathrm{r}}$ even though the OR appears to show no difference is due to the humped nature of the function, such that the median has higher survival than either quartile.

Indices of reliability and calibration indicate that the model has a high rate of discrimination ( $\mathrm{ROC}=0.868$ ), suggesting that the model will perform approximately $87 \%$ as well on a separate dataset. Somers' rank correlation index produced similar results $\left(D_{\mathrm{xy}}=0.736\right)$. However, based on 50 bootstrap replicates, this metric was revealed to be slightly optimistic (0.009), yielding a corrected $D_{\mathrm{xy}}=0.729$. Comparison between observed and corrected probabilities based on bootstrap replicates of predicted values produced only a 0.02 difference in slope and a maximum error in predicted probabilities of 0.01 .

\section{DISCUSSION}

Higher survival or return of fish from semi-natural ponds compared to traditionally hatchery-reared individuals has been observed elsewhere, specifically in searun cutthroat trout (Tipping 1998, 2001), muskellunge Esox masquinongy (McKeown et al. 1999), and coho salmon Oncorhynchus kisutch (Fuss \& Byrne 2002). The difference of survival or recruitment into the spawning population among fish from our sources is the most important source of variation in this analysis as well. Overall, Red Butte Reservoir exhibited much higher recruitment than the other 2 source populations. Survival probabilities of individuals from Camp Creek Reservoir and FES were indistinguishable from each other.

We recognize that stocking from each source population is unreplicated in our analysis, and that confounding effects (e.g. time) possibly produced the apparent difference in survival among sources. How-

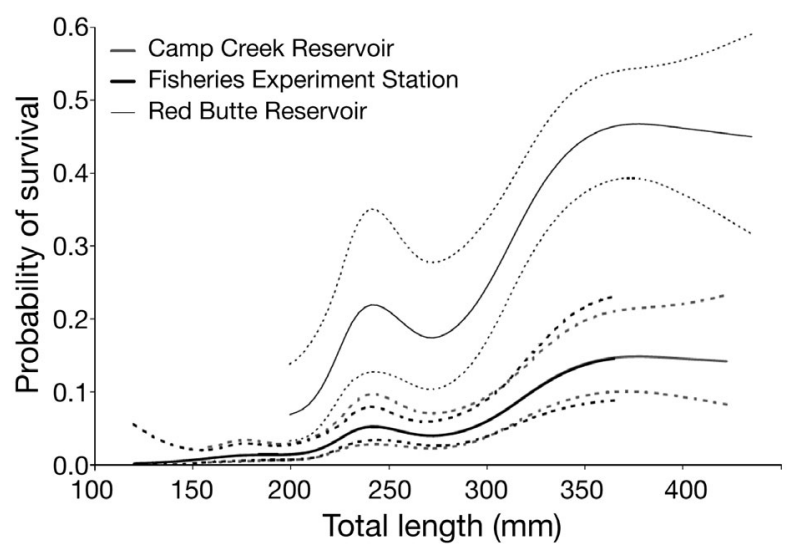

Fig. 2. Chasmistes liorus. Estimated survival probabilities of June suckers stocked into Utah Lake given their original rearing environment and total length at the time of stocking based on a logistic regression model. Dotted/dashed lines represent respective $95 \%$ confidence intervals 
ever, given the number of stocking events that have occurred, the years in which they have occurred, and the limited survival for the vast majority (Table 1), this analysis may be considered as the best case scenario for hatchery and Camp Creek Reservoir survival under the conditions and practices in use at the time (Oksanen 2001, Payne 2006). Nevertheless, unquantifiable factors such as handling differences or vulnerability to capture methods also remain possibilities.

Similarly, inclusion of stocking events excluded from the analysis will do little to increase the power of this analysis. Sixteen recaptured individuals stocked prior to 2005 excluded from the analysis would affect overall conclusions little, but may contribute significantly to overfitting. The 294 individuals from Red Butte Reservoir stocked in 2005 and later recaptured represent a significant number of individuals; however, this number likely greatly underestimates the total number of surviving individuals from this event given insufficient time to recruit into the spawning population. Including this stocking event, therefore, would incorrectly underestimate overall survival of individuals from Red Butte Reservoir. Exclusion of selected stocking events in this analysis, while undesirable, likely produces the most accurate estimates from the available data.

The mechanisms that contribute to variability in observed survival among source locations in our study are unclear. Differing fish length at the time of stocking among the sources is 1 possibility. However, overall survival probabilities remained significantly different among the sites even after statistically adjusting for length by including it in the model. General genetic differences can also be excluded as a possible reason because all fish in this study were from the same genetic stock. A third possibility is that observed differences reflect differing levels of acclimation unique to individuals from each source location.

Artificially reared fish may lack important antipredator characteristics such as cryptic coloration (Maynard et al. 1995) and predator recognition and avoidance behaviors (i.e. behaviorally deficient; Mirza \& Chivers 2000). There is a growing body of research focused on the training or acclimation of hatcheryreared fish for increased survival (Maynard et al. 1995, Brown \& Day 2002, Mueller et al. 2003, Vilhunen 2006). The increase in the probability of survival of fish longer than $200 \mathrm{~mm}$ in our study may indicate that predation of smaller fish is a factor. Introduced species, such as walleye Sander vitreus and white and black bass Micropterus spp., are all probable predators of June sucker up to $200 \mathrm{~mm}$ or more. June sucker share an evolutionary history with a predator (Jordan 1891), a lake-dwelling strain of Bonneville cutthroat trout Oncorhynchus clarki utah. Nevertheless, fish from FES and Camp Creek Reservoir were not exposed to preda- tors during rearing. In contrast, fish from Red Butte Reservoir grew in the presence of cutthroat trout.

Similarly, adaptation to an artificial or sufficiently distinct environment, or even simply growth within an unconstrained, benign environment, may produce individuals morphologically or behaviorally maladapted for a more natural lake environment (Huntingford 2004). For example, Belk et al. (2008) showed that fish from the same family reared in contrasting environments (e.g. hatchery and cages within the lake) exhibited significantly different morphologies. Fish reared in the hatchery had much greater variation both within and among families than did their siblings raised in the semi-natural lake environment. Effects of morphological variation on survival probabilities of June sucker in Utah Lake are unknown, but morphology has been related to performance and survival in other systems (Mesa et al. 1994, McPeek et al. 1996, Downes \& Shine 2001). Likewise, artificially-reared fish may be unable to recognize or consume prey (Ersbak \& Haase 1983, Huntingford 2004).

While the reservoirs are apparently more similar to a natural environment, each differs from Utah Lake and each other in many characteristics such as temperature, turbidity, and zooplankton communities (Thompson 2001, Billman 2005); such differences may contribute to the significant difference in survival probabilities observed between the 2 reservoir sites included in this study. The possibility of maladaptation of reservoir-reared fish for the lake environment remains viable, especially in a long-lived species such as the June sucker. Further research and the creation of selection criteria based on species requirements, considerations of life history traits, and similarity to the natural system for semi-natural ponds may improve the efficiency of using this type of system.

Likewise, culture techniques are constantly assessing progress and adapting, even within programs. June sucker rearing facilities have recently made significant changes that may very well improve the survival of hatchery-reared fish, such as using a warmwater recirculation facility and producing a June sucker- specific feed. Given these and future improvements, this analysis will serve as baseline data against which the successes of the future can be compared and refined. In any event, managers of endangered species recovery programs must not only decide if artificial propagation is appropriate for their species, but also by what methods propagation is accomplished.

Acknowledgements. We thank the many people whose efforts and inputs added to this work, especially K. Wilson and C. Keleher. Likewise, many helpful comments were provided by R. Swanson, D. Routledge, D. Potts, and other JSRIP members. 


\section{LITERATURE CITED}

Anders PJ (1998) Conservation aquaculture and endangered species: Can objective science prevail over risk anxiety? Fisheries 23:28-31

Andersen ME, Keleher CJ, Rasmussen JE, Hansen ES and others (2007) Status of June sucker in Utah Lake and Refuges. Am Fish Soc Symp 53:39-58

Belk MC (1998) Age and growth of June sucker (Chasmistes liorus) from otoliths. Great Basin Nat 58:390-392

Belk MC, Benson LJ, Rasmussen J, Peck SL (2008) Hatcheryinduced morphological variation in an endangered fish: a challenge for hatchery-based recovery efforts. Can J Fish Aquat Sci 65:401-408

Berejikian BA, Tezak EP, Park L, Lahood E, Shroder SL (2001) Male competition and breeding success in captively reared and wild coho salmon (Oncorhynchus kisutch). Can J Fish Aquat Sci 58:804-810

Billman EJ (2005) Population dynamics and foraging ecology of a June sucker (Chasmistes liorus) refuge population. MS thesis, Utah State University, Logan, UT

Billman EJ, Crowl TA (2007) Population dynamics of a June sucker refuge population. Trans Am Fish Soc 136:959-965

Brown C, Day RL (2002) The future of stock enhancements: lessons for hatchery practice from conservation biology. Fish Fish 3:79-94

Bruton MN (1995) Have fishes had their chips? The dilemma of threatened fishes. Environ Biol Fishes 43:1-27

- Cooke SJ, Bunt CM, Cooperman MS, Jennings CA, Hamilton SJ, Pearson MP, Markle DF (2005) Threats, conservation strategies, and prognosis for suckers (Catostomidae) in North America: insights from regional case studies of a diverse family of non-game fishes. Biol Conserv 121: 317-331

Davis JLD, Williams-Young AC, Aquilar R, Carswell BL, Goodison MR, Hines AH, Kramer MA (2004) Differences between hatchery-raised and wild blue crabs: implications for stock enhancement potential. Trans Am Fish Soc 133:1-14

Downes S, Shine R (2001) Why does tail loss increase a lizard's vulnerability to snake predators? Ecology 82: 1293-1303

Enfron B, Tibshirani R (1993) An introduction to the bootstrap. Chapman \& Hall, New York

Ersbak K, Haase BL (1983) Nutritional deprivation after stocking as a possible mechanism leading to mortality in stream-stocked brook trout. N Am J Fish Manag 3: $142-151$

Fuhriman DK, Merritt LB, Miller AW, Stock HS (1981) Utah Lake monograph: hydrology and water quality of Utah Lake. Great Basin Nat 5:43-67

Fuss H, Byrne J (2002) Differences in survival and physiology between Coho salmon reared in seminatural and conventional ponds. N Am J Fish Manag 64:267-277

Gerber LR, Hatch LT (2002) Are we recovering? An evaluation of recovery criteria under the U.S. Endangered Species Act. Ecol Appl 12:668-673

Hard JJ, Jones RP Jr, Delarm MR, Waples RS (1992) Pacific salmon and artificial propagation under the Endangered Species Act. National Oceanic and Atmospheric Administration, Seattle, WA

Harrell FE Jr (2001) Regression modeling strategies: with applications to linear models, logistic regression, and survival analysis. Springer, New York

Harrell FE Jr (2007) Design: design package, R version 2.1-1. Available at: http://biostat.mc.vanderbilt.edu/twiki/bin/ view/Main/Design
Heckmann RA, Thompson CW, White DA (1981) Utah Lake monograph: fishes of Utah Lake. Great Basin Nat 5: 107-127

Hosmer DW, Lemeshow S (2000) Applied logistic regression. John Wiley \& Sons, New York

Huntingford FA (2004) Implications of domestication and rearing conditions for the behaviour of cultivated fishes. J Fish Biol 65:122-142

Ireland SC, Anders PJ, Siple JT (2002a) Conservation aquaculture: an adaptive approach to prevent extinction of an endangered white sturgeon population. Am Fish Soc Symp 28:211-222

Ireland SC, Beamesderfer RCP, Paragamian VL, Wakkinen VD, Siple JT (2002b) Success of hatchery-reared juvenile white sturgeon (Acipenser transmontanus) following release in the Kootenai River, Idaho, USA. J Appl Ichthyol 18:642-650

Jordan GS (1891) Report of exploration in Colorado and Utah during the summer of 1889, with an account of the fishes found in each of the river basins examined. Bull US Fish Comm 9:1-40

Kohler CC (1995) Captive conservation of endangered fishes. In: Gibbons EF Jr, Durrant BS, Demarest J (eds) Conservation of endangered species in captivity. State University of New York Press, Albany, NY, p 77-86

Le Vay L, Carvalho GR, Quinitio ET, Lebata JH, Ut VN, Fushimi H (2007) Quality of hatchery-reared juveniles for marine fisheries stock enhancement. Aquaculture 268: 169-180

Leidy RA, Moyle PB (1997) Conservation status of the world's fish fauna: an overview. In: Fiedler PA, Karieva PM (eds) Conservation biology for the coming decade. Chapman, New York, p 187-227

Maynard DJ, Flagg TA, Mahnken CVW (1995) A review of innovative culture strategies for enhancing the postrelease survival of anadromous salmonids. Am Fish Soc Symp 15:307-314

McKeown PE, Forney JL, Mooradian SR (1999) Effects of stocking size and rearing method on muskellunge survival in Chautauqua Lake, New York. N Am J Fish Manag 19:249-257

McPeek MA, Schrot AK, Brown JM (1996) Adaptation to predators in a new community: swimming performance and predator avoidance in damselflies. Ecology 77: $617-629$

Meffe GK (1986) Conservation genetics and the management of endangered fishes. Fisheries 11:14-23

> Mesa MG, Poe TP, Gadomski DM, Petersen JH (1994) Are all prey created equal? A review and synthesis of differential predation on prey in substandard condition. J Fish Biol 45(Suppl A):81-96

Mirza RS, Chivers DP (2000) Predator-recognition training enhances survival of brook trout: evidence from laboratory and field-enclosure studies. Can J Fish Aquat Sci 78: 2198-2208

Moyle PB, Leidy RA (1992) Loss of biodiversity in aquatic ecosystems: evidence from fish faunas. In: Fiedler PL, Jain $\mathrm{K}$ (eds) Conservation biology: the theory and practice of nature conservation, preservation, and management. Chapman, New York, p 127-169

> Mueller GA, Marsh PC, Foster D, Ulibarri M, Burke T (2003) Factors influencing poststocking dispersal of razorback sucker. N Am J Fish Manag 23:270-275

> Oksanen L (2001) Logic of experiments in ecology: is pseudoreplication a pseudoissue? Oikos 94:27-38

Palmer MA, Bernhardt ES, Allan JD, Lake PS and others (2005) Standards for ecologically successful river restora- 
tion. J Appl Ecol 42:208-217

Payne RW (2006) New and traditional methods for the analysis of unreplicated experiments. Crop Sci 46:2476-2481

Pope KL, Kruse CG (2007) Condition. In: Guy CS, Brown ML (eds) Analysis and interpretation of freshwater fisheries data. American Fisheries Society, Bethesda, MD, p 423-472

R Development Core Team (2008) R: a language for statistical computing version 2.6.2. Vienna. Available at www. R-project.org

Ricciardi A, Rasmussen JB (1999) Extinction rates of North American freshwater fauna. Conserv Biol 13:1220-1222

Ryman N, Laikre L (1991) Effects of supportive breeding on the genetically effective population size. Conserv Biol 5: $325-328$

Scoppetone GG, Vinyard G (1991) Life history of four endangered lacustrine suckers. In: Minckley WL, Deacon JE (eds) Battle against extinction: native fish management in the American west. University of London Press, Tucson, AZ, p 359-378

Stone CJ, Koo CY (1985) Additive splines in statistics. Proc Stat Comput Sect ASA 1985:45-48

Stoskopf MK (1995) Design of captive environments for endangered fishes. In: Gibbons EF Jr, Durrant BS, Demarest J (eds) Conservation of endangered species in captivity. State University of New York Press, Albany, NY, p 125-142

Thompson PD (2001) June sucker (Chasmistes liorus) moni-

Editorial responsibility: David Agnew,

London, UK toring and transfer activities in the northern region. Utah Division of Wildlife Resources, Salt Lake City, UT

Tipping JM (1998) Return rates of hatchery-produced sea-run cutthroat trout reared in a pond versus a standard or baffled raceway. Prog Fish-Cult 60:109-113

Tipping JM (2001) Adult returns of hatchery sea-run cutthroat trout reared in seminatural ponds for differing periods prior to release. N Am J Aquac 63:131-133

Unwin MJ (1997) Fry-to-adult survival of natural and hatchery-produced Chinook salmon (Oncorhynchus tshawytscha) from a common origin. Can J Fish Aquat Sci 54: 1246-1254

USFWS (1999) June sucker (Chasmistes liorus) recovery plan. United States Fish and Wildlife Service: Region 6, Denver, $\mathrm{CO}$

Vilhunen S (2006) Repeated anitipredator conditioning: a pathway to habituation or to better avoidance. J Fish Biol 68:25-43

Wege GJ, Anderson RO (1978) Relative weight (Wr): A new index of condition for largemouth bass. In: Novinger $G$, Dillard J (eds) New approaches to the management of small impoundments. North Central Division: American Fisheries Society, Bethesda, MD, p 79-91

Whitney M, Belk MC (2000) Threatened fishes of the world: Chasmistes liorus Jordan, 1878 (Catostomidae). Environ Biol Fishes 57:362

Zar JH (1999) Biostatistical analysis. Prentice Hall, Upper Saddle River, NJ

Submitted: March 25, 2009; Accepted: July 3, 2009

Proofs received from author(s): September 14, 2009 